\title{
Profile of Students Communication Skills on Global Warming and Pollution Subject Using Conference Assessment
}

\author{
T. Gustiani ${ }^{1}$, W. Ana Ratna ${ }^{2,3}$ and R. Solihat ${ }^{2,3}$ \\ ${ }^{1}$ Biology Education Department of Post-Graduate Program, Universitas Pendidikan Indonesia \\ (UPI). J1. Dr. Setiabudi 229, Bandung, 40154, Indonesia \\ ${ }^{2}$ Universitas Pendidikan Indonesia (UPI), Jl. Dr. Setiabudi 229, Bandung, 40154, Indonesia \\ ${ }^{3}$ Corresponden Author \\ E-mail: gustianitia@gmail.com
}

\begin{abstract}
This research purpose is to analyze the student's communication skills using the conference assessment and student response of conference assessment implementation on global warming and pollution subject. The method used is descriptive. Participants included 34 students $11^{\text {th }}$ grade in senior high school. Conference assessment applied through project based learning on global warming and pollution subject. Conference assessment consists of written conference using online access and oral conference in face-to-face classrooms. The conference was held in three sessions (project planning, project work, and project reflection). Students communication skills consist of five indicators based on $21^{\text {st }}$ skills. The indicator was 1) articulate thoughts and ideas effectively; 2) listen effectively; 3) use communication for a range of purposes; 4) utilize multiple media and technologies; and 5) communicate effectively in diverse environments. The average score of communication skill skills categorized into three groups: high, medium and low. The data showed that three indicators in high categorized $83.09 \%$ in the second indicator during oral conference, $77.94 \%$ in the fourth indicator and $88.97 \%$ in the fifth indicator). And three indicators in medium categorized $(64,71 \%$ in the first indicator, $56.62 \%$ in second indicator during written conference and $69.85 \%$ in the third indicator). Students showed a positive response to the implementation and results of conference assessment.
\end{abstract}

\section{Introduction}

Communication is one of the key components of $21^{\text {st }}$-century learning. The student needs communication skill to be successful in work and life [1]. Traditionally, educational interactions have been based upon oral communications between and among teachers and learners. But, in $21^{\text {st }}$-century skills, face-to-face communication is seen as the "gold standard," so students develop few capabilities in mediated dialogue and shared design within a common virtual workspace [2]. Some research develops written communication using CMC (Computer Mediated Conference) [3,4,5]. The results show that this written conference facilitates a collaborative communication process to build meaningful and valuable knowledge. Oral communication in a face-toface context provides multiple non-verbal or paralinguistic cues such as facial 
expression and tone of voice. But, oral communication tends to be fast-paced, spontaneous, fleeting, and less structured than text-based communication. One such advantage is that text-based communication provides time for reflection, this process provides higher-order cognitive learning.

The P21 Framework provides a conceptualization of $21^{\text {st }}$-century emphasizes articulate thoughts and ideas effectively using oral, written and nonverbal communication skills in a variety of forms and contexts; listen effectively to decipher meaning, including knowledge, values, attitudes and intentions; use communication for a range of purposes (e.g. to inform, instruct, motivate and persuade); utilize multiple media and technologies, and know how to judge their effectiveness a priori as well as assess their impact; communicate effectively in diverse environments (including multilingual) [6]. This conceptualization reflects communicative competence, (CMC) Computer Mediated Communication, and interpersonal immediacy behaviors. omputermediated communication (CMC) systems, in a variety of forms, have become integral to the initiation, development, and maintenance of interpersonal relationships [12].

The conference is one of alternative assessment and can be used more widely as part of an evaluation. The conference is advantageous for understanding the processes, strategies and approach student use in the performance of school work and task. The main purposes of these conference sessions were the following to allow the instructor and the students to talk about learning different grammar points constructively; to provide both the teacher and the students with an invaluable source of information about the students' progress in their learning; to identify the gaps in the students' understanding of the subject matter as well as to provide them with the necessary positive feedback to motivate them, and (d) to create a supportive atmosphere for the students to experience problem solving and information sharing processes [7]. In this study, researcher combined oral and written conference assessment to assess student communication skill.

\section{Method}

The method of study was descriptive. The participants for this study were 34 students $11^{\text {th }}$ grade in senior high school (17 females and 17 males). Participants were divided into seven discussion groups. The instrument used in this study was conference checklist, commFunication rubric and questionnaire. Conference checklist was a set of questions to be asked by the teacher during online conference and face to face conference. Communication rubric was a scoring tool used to evaluate and assess a set list of communication criteria. The rubric had five indicator criteria and four-point scale (1-4). Criteria on the rubric based on P21 Framework. The questionnaire consists of questions about the student's response to the conference activities.

Learning methods were project-based learning. The project was created a poster about global warming and pollution (water, air and land pollution). Teachers gave different themes to each group. The conference was divided into three sessions (project planning, working and evaluating). 
1. First session conference about project planning using Line as online conference media. The questions were poster ideas, poster design, tools, materials and student difficulties during planning project.

2. Second session conference about project working using face-to-face conference at classroom. Teachers take turns conducting conferences on each group for five minutes. The questions were student contribution at group, student difficulties during planning project, strengths and weaknesses of product.

3. Third session conference about project evaluating using Line as online conference media. The questions were student problem; how to solve the problem; student strengths and weaknesses; student understanding; student response about their score; and self-reflective.

\section{Result and Discussion}

\subsection{Students Communication Skill}

Scores were obtained through rubric assessments during the conference. The average score result showed in Figure 1. The distribution of student communication skill in each indicator showed in Table 1.

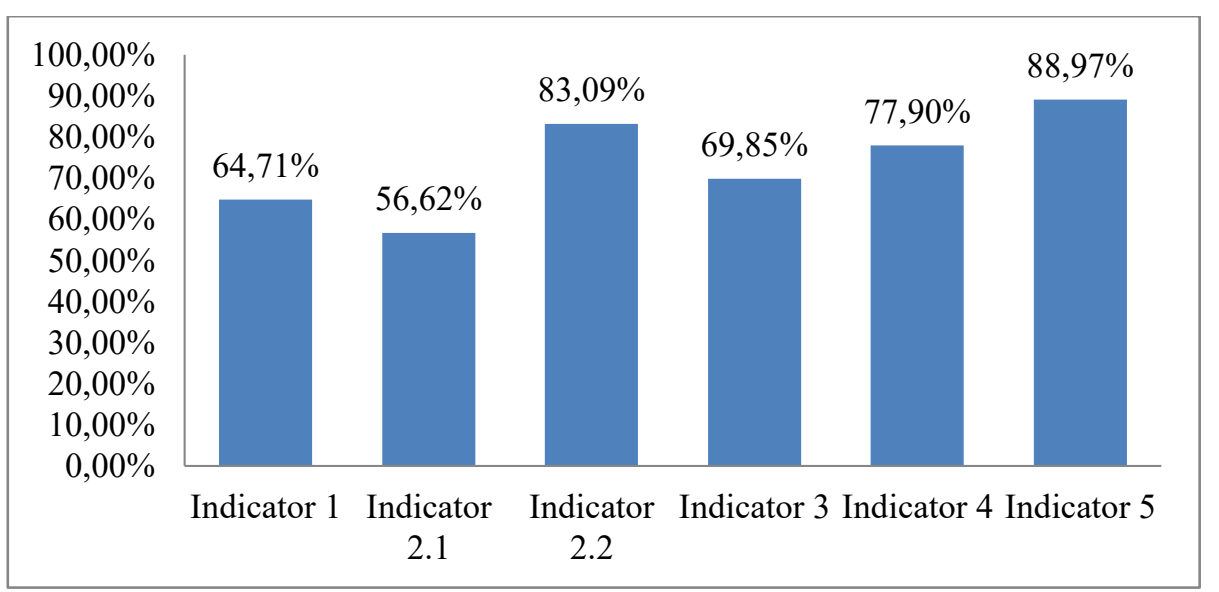

Figure 1. The Average of Student Communication Skills Profile

Table 1. Data of Communication Indicators Distribution

\begin{tabular}{ccccccc}
\hline \multirow{2}{*}{ Indicator } & \multicolumn{3}{c}{ Category } & \multicolumn{3}{c}{ Percentage (\%) } \\
& High & Medium & Low & High & Medium & Low \\
\hline 1 & 10 & 19 & 5 & 29.41 & 55.88 & 14.71 \\
$2 \mathrm{a}$ & 8 & 14 & 12 & 23.53 & 41.18 & 35.29 \\
$2 \mathrm{~b}$ & 18 & 16 & 0 & 52.94 & 47.06 & 0 \\
3 & 11 & 19 & 4 & 32.35 & 55.88 & 11.76 \\
4 & 11 & 23 & 0 & 32.35 & 67.65 & 0 \\
5 & 26 & 8 & 0 & 74.47 & 23.53 & 0 \\
\hline
\end{tabular}

Specification:

Indicator 1: articulate thoughts and ideas Effectively

Indicator 2a: Listen Effectively in written communication

Indicator 2b:Listen Effectively in oral communication

Indicator 3: Use communication for a range of purposes 
Indicator 4: Utilize multiple media and technologies

Indicator 5: Communicate effectively in diverse environments

The average score of communication skill of the first indicator was $64,71 \%$ (category: medium). The percentage of student in the high category was $29.41 \%$. The student can articulate thoughts and ideas effectively using oral communication skills during oral conference and written communication skills during written conference. Effectively communication was seen from the conformity of ideas with themes. The percentage of student in medium category was $55.88 \%$, the student only articulate thoughts and ideas at oral conferences. This result was supported by the student's response in the questionnaire. Students argued difficult to articulate written ideas. The percentage of student in low category was $14.71 \%$. Student can't articulate thoughts and ideas in both of conference.

The average score of communication skill of the second indicator during written conference was $56.62 \%$ (category: medium). The percentage of student in high category was $23.53 \%$. The student can listen effectively to decipher meaning, including knowledge, values, attitudes and intentions in written conference. Listen effectively skill was seen from student responses to the opinions of others. The percentage of student in medium category $41.18 \%$, student only provide approval and rebuttal to other students without reason. The percentage of student in low category was $35.29 \%$. Student didn't provide response to other student's opinion. Some students had difficulty expressing opinions and responses in writing.

The average score of communication skill of the second indicator during oral conference was $83.09 \%$ (category: high). The percentage of student in high category was $52.94 \%$. Student can listen effectively to decipher meaning, including knowledge, values, attitudes and intentions in oral conference. Listen effectively skill was seen from student responses to the opinions of others. The percentage of student in medium category $47.06 \%$, student only provide approval and rebuttal to other students without reason. There was no students included in low category. These results showed that student was more comfortable doing oral conference than written conference. This result proved that oral or face-to-face communication is seen as the "gold standard" in communication skill [2]. This result was same as the result of first indicator. The questionnaire result showed that $58.82 \%$ student like oral conference. Student argue that oral conference provide fast responses and easier than written conference. There was $17.65 \%$ student like written conference and $23.53 \%$ student like combination conference. They argued that written conference provide them time to reflect and think before give response and opinion. This result proved that text-based communication provides time for reflection, this process provide higher-order cognitive learning [3].

The average score of communication skill of the third indicator was $69.85 \%$ (category: medium). The percentage of student in high category was $32.35 \%$. Student can use communication for a range of purposes (e.g. to inform, instruct, motivate and persuade). There was 1-2 student in each group who involved in high category. $90 \%$ 
student who involved in high category was female. The percentage of student in medium category was $55.88 \%$, student can use communication for 2-3 purposes. The percentage of student in low category was $11.76 \%$. Student only using communication for inform.

The average score of communication skill of the forth indicator was $77.94 \%$ (category: high). The percentage of student in high category was $32.35 \%$. Student can utilize multiple media and technologies, and know how to judge their effectiveness a priori as well as assess their impact. Technology used during learning is Line and Google classroom. Line used as technology for online conference. Google classroom was used for task regulation and submit publication links. In high category, student can download task, submit work result and publication links in Google classroom. Besides that, student can utilize the Line feature to send links, documents or pictures, not only use Line for conversation or chat. The percentage of student in medium category was $67.65 \%$. Student can operate Google classroom, but only use Line for conversation or chat. The percentage of student in low category was $0 \%$. This result showed that Google classroom and Line was easy to use as technology during learning process.

The average score of communication skill of the fifth indicator was $88.97 \%$. (category: high). The fifth indicator was communicating effectively in diverse environments (including multi-lingual). In this study, the researcher limited the diverse environment only in school environment and virtual environment (social media). The percentage of student in high category was $74.47 \%$. Students were able to publish products through class presentations and social media publications. Student can describe the product clearly in both of environment. The percentage of student in medium category was $23.53 \%$. in medium category, student only publish products through class presentations. No students included in low category in this indicator.

\subsection{Students' Response to The Use of Conference Assessment}

Table 2. Students' Response to Conference Assessment

\begin{tabular}{llccc}
\hline \multicolumn{1}{c}{ Response } & Whole & Most & Few & No \\
\hline Help overcome learning difficulties & $2.94 \%$ & $58.82 \%$ & $35.29 \%$ & $0.00 \%$ \\
Understand learning process and strategy & $0.00 \%$ & $73.53 \%$ & $23.53 \%$ & $0.00 \%$ \\
Self-reflection & $17.65 \%$ & $61.76 \%$ & $17.65 \%$ & $0.00 \%$ \\
Improve student performance & $14.71 \%$ & $55.88 \%$ & $26.47 \%$ & $0.00 \%$ \\
Improve written communication skill & $5.88 \%$ & $55.88 \%$ & $35.29 \%$ & $0.00 \%$ \\
Improve oral communication skill & $11.77 \%$ & $64.71 \%$ & $20.95 \%$ & $0.00 \%$ \\
\hline
\end{tabular}

Table 2. showed the result of questioner about student response to conference assessment. This data showed that student had positive response to the implementation and results of conference assessment. Most of student argued that conference assessment can help overcome learning difficulties; understand learning process and strategy; self-reflection; improve student performance; improve written and oral communication skill. There was no negative respond to conference assessment process. 
Conference assessment provides more times to teacher give feedback [8]. Teacher feedback can improve student performance in the learning process. Feedback was part of learning process, not only given after learning proses or evaluation [9].

Conference assessment focused on student weaknesses and strengths. This process helps student and teacher to improve their learning process [8,10]. Students assess themselves, reflect, monitor and communicate their own progress during conference. Students take the responsibility of their own learning. At the same time this engagement in this process of improvement and decision making motivate students to learn and try to improve their capabilities as reflected in the results. This process during conference can help students understand learning strategies and processes, and reflect on the learning progress; helps learners to build better self-images (self-images); help students express their learning difficulties; as well as train students responsible for the learning they are doing and learning achievement [8,10,11]. Using alternative assessment techniques can provide useful information about the process of learning. This diagnostic information besides feedbacks to the learner helps to remove the gap between what has been taught and what has been learned.

\section{Conclusion}

The profile of students' communication skill in each indicator was included in high and medium category. Students showed positive response to the implementation and results of conference assessment. Conference assessment can improve learning process between teacher and student.

\section{Acknowledgement}

Thanks to SMAN 1 Lembang, Mrs Noverita, and all participant from X MIPA 2 to has contribution in this study.

\section{References}

[1] Griffin, P., McGraw, B. \& Care, E. (2012). Assessment and Teaching of 21st Century Skills. New York: Springer Science+Business Media

[2] Bellanca, J. A. \& Brandt, R. S. (2010). $21^{\text {st }}$ Skills Rethingking How Student Learn. United States of America: Solution Tree Press.

[3] Garrison, D. R., Anderson, T. \& Archer, W. (2000). Critical Inquiry in a TextBased Environment: Computer Conferencing in Higher Education. The Internet and Higher Education 2(2-3), pp. 87-105.

[4] Garrison, D.R., Anderson, T., \& Archer, W. Critical thinking, cognitive presence, and computer conferencing in distance education. American Journal of Distance Education, 15(1), pp. 7-23.

[5] Anderson, T., Rourke, L., Garrison, D.R. \& Archer, W. (2001). Assessing Teaching Presence in a Computer Conferencing Context. JALN, 5 (2).

[6] Partnership for 21st Century Skills 2015 P21 Framework Definitions (Washington DC: $\quad$ A Partnership for 21st Century Skills) Black P, Harrison C, Lee 
C, Marshall B and William D 2004 Working Inside The Black Box: Assessment for Learning in The Classroom SagepubJournal 91

[7] Stiggins, R. J., \& Chappuis, J. (2005). Using studentinvolved classroom assessment to close achievement gaps. Theory into Practice, 44(1), pp.11-18.

[8] Genesee, F., \& Upshur, J. (1996). Classroom-based evaluation in second language education. Cambridge: Cambridge University Press.

[9] Scott, J. (2003). Authentic Assessment Tools. Educational Research Information Center.

[10] Brown, J. D., \& Hudson, T. (1998). The Alternatives in Language Assessment. TESOL Quarterly, 32(4).

[11] Stiggins, R. J. (1994). Student-Centered Classromm Assessment. New York: Macmillan College Publishing Company.

[12] Walther, J. B. (1996). Computer-mediated communication impersonal, interpersonal, and hyperpersonal interaction. Communication research, 23(1), $3-43$. 